mit, as shown in all our English hoepitals, has had roconise to the median operation of Allarton, with quite gratifying results. An old nurse or "sister", whose opinion on such a point may correct much false theory at present and much falser prejudice, has observed at Bartholomew's that all old stone cases die except Mr. Lloyd's. From what we have seen of all the smaller hospitals, and from time to time of Guy's, King's College Hospital, St. Thomas's, the London Hospital, etc., there appears much sense and practical value in this observation.

Mr. Hintor has had, at Guy's Hospital, a case of extraction of stone in a female, where a hair-pin had been passed into the bladder. The case is doing very well.

FORMIDABLE OPERATION ON THE JAW: RELATIVE VALUE OF CHLOROFORM AND ICE AS ANRSTHETICS.

Mr. MLCK muRdo performed a very fearful operation at St. Thomas's Hospital, on the 9 th inst. We say tremendous or fearful, as there is really no other word to explain or express the formidable proceeding of cutting out a huge tumour, the size of a cocoa-nut, from the upper jaw; this tumour having its deeper attacliments close upon the styloid process and internal carotid in the petrous bone, covered or mixed up also with the pterygoid muscles, and engaging externally the zygoma, and all the side of the jaw and face. The nature of the tumour itself, as to its malignancy or recurrent character, unfortunately did not seem to afford much room for speculation or doubt; while its deep attachments were not ascertained till Mr. Mackmurdo got on the carotid, and had isolated the growth from the mass of surrounding textures. The opinion, however, seems gaining ground, that these growths usually have their origin at the base of the cranium, more especially about the basilar process of the occipital bone or its vicinity.

A practical classification of these growths from the upper jaw has been made, and is observed at St. Bartholomew's, and some other hospitals. First, epulis, so familiar to the surgeon; then cystic tumours, with the walls of the bone expanded on or into a sac, with more or less of solid growth; thirdly, cartilaginous or osseous tumours, growing on the outside of the upper maxilla, this thickening often very dense and hard; fourthly, fibrous tumours, with cavities containing pus, or a glairy fluid like glue, or eren actual blood. The tumour in the present case of Mr. Mackmurdo's was thought to be of this nature, if not bordering on the fifth and final division, namely, malignant or medullary tumours, consisting of various round, lobed, or nodulated masses, with a smooth membranous covering, or with a rough fungous or ulcerated shreddy surface, invested by a thick capsule, by a dense periusteum, or by partial thin laminæ of bone, sometimes commencing primarily in the neighbouring glands, and extending to the jaws secondarily.

In this instance, Mr. Mackmurdo first considered that the tumour had commenced in the " socia parotidis". The early history of the case did not throw the least light on the subject. Ice and various other therapeutic means had been tried in vain to reduce its size. Mr. Mackmurdo, we believe, was not very sanguine as to any permanent benefit from the operative proceeding; yet, as the young man and his friends wished to have the tumour removed, be complied with their desires. The case, indeed, is only interesting or instructive, as a sort of commentary on the fact, which almost every week turns up, that a patient wishes to have something done, though the surgeon cannot promise a curc. The operation was performed, as is usual in operations about the mouth, without chloroform; the patient seeming to suffer very little from the various incisions, as if the tumour was not rery highly organised, or, as it struck us at the time, that the fifth and seventh nerves were completely paralysed, from the growth pressing on these nerves, and inveding all the parts about the locality where the fifth leaves the carserian ganglion, and the seventh dips into the parotid. Mr. Mackmurdo commenced the operation by a long incision from the angle of the mouth at the left side, accomplished, when growth, now reduced to the size of an orange, filled up all the maxillary space, the bones in some places being absorbed. Several large vessels, the facial, the internal maxillary, etc., here bled profusely, requiring ligatures; and a large quantity of fluid poured from a cyst, apparently, which had been cut into. It appeared well that chloroform had not been used, as the young man, at this stage of the operation, appeared quite faint, and was fed with wine. Mr. Mackmurdo meanwhile separated more of the tumour by means of his fingers and the handle of the knife; but, as we have already said, when he had reached the deep layers of the cervical fascia forming the stylo-maxillary ligament, the pterygoid muscles, and internal carotid, it was thought prudent to separate the tumour, and bring together the parts. We believe that ice as a local anæsthetic might be used with advantage, in such cases as this, for the first incisions; but chloroform would be most hazardous, if not fatal.

K.

\section{OHinginal CLommunatations.}

\section{ILLUSTRATIONS OF THE PATHOLOGY OF CANCER. \\ By J. Zachariah Licrence, Esq., F.R.C.S. PART I. \\ GENERAL CHARACTERS AND CLASSIFICATION OF CANCEROUS TUMOURS.}

CaNCER, or carcinoma, is a name of extreme antiquity, derived, in the first instance, from fanciful similes. * MALIGNANT is a term of comparatively modern origin. Of the two, the former is preferable. For while it, on the one hand, possesses the great merit of implying nothing further than the immediate object of its designation, it, on the other hand, has so engrafted itself on the languages of nations, that to ignore its existence would be but pedantry.

The definitions which different authors have imposed on the words Cancer and Malignant Growths have been of a twofold nature: either they have, aiming at simplicity, endeavoured to identify the class of growths in question with one single attribute, $\dagger$ or they have, with perhaps less regard to analogy with the exact sciences, but with more to that of truth, applied these names to a class of adventitious products, possessing an assemblage of attributes in a greater or a less degree. Abernethy has very appositely compared the different species of tumours to the primary colours of the spectrum, between which there exist all intermediate phases; so that, to pursue Abernethy's simile, even supposing we had arrived at exact definitions for the primary colours, those definitions would be more or less inapplicable to the transitional tints.

The following characters constitute the main features of cancerous growths :-

1. Their fatality is often independent of any local effect at all adequate to account for such fatality.

2. Their vegetative property; the reproduction of growths sinilar to themselves in different textures of the organism.

3. Their almost constant liability to local recurrence after the most complete surgical operations.

- The distended subcutaneous reins have been compared to the clavrs of a crab, of which the tumour represented the body. "Tumor evadit magrus et curn renis circa circumtumentibus et liventibus instar pedum cancrinomes et curn renis circa circumtumentibus ct liventibus instar pedum cancrinorus, unde etiam nomen habet, se prodit." (Ettmuller, De Morlis fromum,
Mulierum et Infantum, cap. 10.) Awbroise Puré seeks to impress the name Mulierum et Infantum, cap. 10.) Awbroise Pure seeks to impress the name
by an actual drawing of a crab. " $D^{\prime}$ autres auteurs ont expliyjue ce nom par by an actual drawing of a crab. "D'autres auteurs ont expliygue ce nom par
rapport a la douleur rongeante que cause cet horrible mal." (Tratte dre rapport d la douleur rongeante 9

Cancer, par Alliot. Paris: 169R.)

t To this class belong Lebert and his followern. This second character, it may be noted, includes in its terms the almost lymphatic glanda. 
4. Their indiscriminate involvement of all the tissues, hoalthy or morbid, they meet with in their progressive growth.

Of these four features the first two are especially distinctire. It will, doubtless, be remarked that in the above definition I have altogether ignored the anatonical charecters of growths. This, however heterodox it may appear to the morbid anatomist, will be vindicated in the classification we shall have presently to exhibit. It will there be seen that no general features of malignancy can be founded on mere anatomical structure : that grow ths differing widely in their rough and minute anatomy may agree closely in their clinical course and terminations. I am not singular in this opinion. One of the most philosophical pathologists of the day has well observed, " the distinction between innocent and malignant tumours is probably one not of mere visible structure, but of origin and vital properties." Carl Wedl, too, whose work one could have imagined would have given his thoughts an opposite tendency, has equally well remarked that " the idea of malignancy of new formations is only relative, connected with $n$ dycrasis of the blood, which has not yet been clucidated."

Designating, then, by the terms Malignant Grouths, or Cancer, all growths which possess, in a greater or less dcgree, the clinical attributes enumerated above, we may again subdivide them into so many species, according to their anatomical peculiarities.* Proceeding on this principle, we have the following classification:-

Genus: Mahignant Growtus.-Cancer (Auctoris). Species.

1. Scirrhus 2 Encephaloid $\}$ Cancer, vulgo sic dict.

3. Melanosis.

4. Nevoid Cancer (?) (Auctoris).

5. Villous Cancer (?) (Rokitansky).

6. Osteoid Cancer (Müller, Paget).

7. Enchondromatous Cancer (Auctoris).

8. Colloid Cancer.

9. Fibrous Cancer (Paget).

10. Fibroplastic Cancer (Velpeau).

11. Epithelial Cancer (Paget, Schuh).

The following explanatory commentaries on these several species of cancer may not be misplaced :-

(1) Scirrios and (2) ENCEPHALOID constitute the great mass of cancerous tumours, of which they are the generally accepted representatives.

(3) Menaxosis has been admitted as a distinct species rather from its clinical relations than from its anatomical structure. That in this latter particular it is nothing more than encephaloid impregnated with pigment is casily demonstrable; but the special ages and localities it affects, and its high degree of vegetative faculty, entitle it unquestionably to a distinct specific position.

The following case affords a good illustration of the disease :-

CAsE. Melanosis of the Eye-ball: Operation: Death, with Secondary Deposits on the Brain, in the Lungs, Liver, and Mesenteric Glands. Charles $\mathrm{L}$. was aged 53 years when he was admitted into University College Hospital, under Mr. Erichsen, for a tumour of the left eye-ball. Some eight or nine years before his admission into the hospital he received a blow above the left ejebrow from an iron rod; he did not experience any great pain in the eye, but the sight of it gradually dwindled away, till at last it was entirely gone. Seven years afterwards he was under $\mathrm{Mr}$. Moore at the Middlesex Hospital for what is entered in that gentleman's case-book as "inflammation in an eye destroyed seven years ago by traumatic inflammation; eye large, and full of green lymph." The eye continued red, and occasionally painful, for a year after, and about this time (eleven to twelve months ago) he first began to notice it swelling.

- The anatomical characters of the rarer species (Nos. 3 to 10) are illus. trated by the cases adduced: those of scirrhus, encephsloid, and opithelioma are sntieiently well known, 80 ks not to need sny further illustration here.
He has lost a good deal of flesh, but otherwise his health has been pretty good. The tumour has never bled, excepting slightly in removing the dressings.

The following notes were taken a week before he was operated on :-

Local Appearances. Projecting from between, and displacing the eyelids, is a tumour, reaching from the outer canthus to nearly the side of the nose ; its greatest measurements are, from above downwards, one inch and aquarter; from side to side, two inches. The surface of the tumour is smooth; its colour dingy, light, purplishred; its feel hard, with a certain degree of elasticity, though retaining, at some spots, the impression of the fingers. The cornea is shrunken, and externally angular in outline; the pupil is filled with an opaque, whitish-buff substance, and its form distorted. The eyelids are not hypertrophied; the lower one bulges inferiorly, is pale and cedematous; the upper one is but little altered in appearance. There is a thin discharge from the tumour, never, as far as he has observed, of an offensive character. He has not suffered any pain in the eye for some time now when he did, it was of the most acute description, and was felt principally in the supraorbital and occipital regions. He states he can still distinguish light from darkness with the eye.

General Appearance of the Patient. He is tall and excessively wasted. His feutures are pinched, his cheeks sunken, his face partaking, in fact, in the general emacistion of the body. His complexion is remarkably dingy and icteric, his hair black, his right eye dark. He is a very intelligent man, and gives a straightforward account of his malady.

His parents died at an advanced age. His mother's sister had some tumour of the breast, of which he thinks she died. IIis own health had always been good; he never exhibited any phthisical or rheumatic tendency.

Mr. Erichsen remored the tumour by the ordinary method; in order, however, to ensure its complete destruction, after he had dissected out all that could be felt or seen of the growth, he applied the actual cautery to the entire surface of the orbital cavity -a proceeding calculated also to arrest any hæmorrhage that might ensue.

In order to present the reader with the whole of the anatomical features of this case at once, I shall defer noticing the characters of the growth till I have briefly related the further progress of the case.

All went on well till a fortnight after the operation, when he began to be troubled with transient shooting pains in the orbit, and in eleven days afterwards an irritative form of diarrhœea set in; however, it was not till about six weeks after the operation that any symptoms occurred calculated to create much apprehension. He was then seized with an epileptiform fit; and when I saw him on the following day, he returned no answer to me when I spoke to him, although he kept his eye fixed on me, following me, when I was leaving the ward, as if he knew me; yet I do not think he possessed much remaining consciousness. He moved all his limbs well. The pupil was moderate in size, and acted pretty well. His tongue was thickly coated with a moist white fur; his pulse was 140 (his average pulse was 80 before). His general conditien reminded me altogether a good deal of what I had observed in several cases of traumatic affections of the brain under the name of "cerebral irritation." When I saw him two days afterwards, he was dying. His face and body generally were covered with a profuse sweat; he was in a state of extreme exhaustion, yet, to all appearances, conscious. His pulse was about 160 ; very unequal and fluttering; his respirations 48; his tongue dry, rough, and brown; his pupil of medium size, acting well. He died the following day.

anatomy of tue Primary Tumodr. The tumour was, at the first glance, seen to be melanotic cancer of the ejeball. The special relatious of the melanotic deposit were well exhibited by a section through the middle of the tumour, carried from behind forwards through the mass of the growth and the remains of the shrunken ejeball. The 
conlar conjunctiva was found greatly expanded, and, at the came time, thickened; the sclerotic coat was comparatively unaltered, although shrunkeu and wrinkled. Between these two tunics lay the chief mass of the tumour. This consisted of a layer of firm, lobulated tissue, of a deep bistre colour, which adhered but loosely to the inner surface of the conjunctiva, but very intimately and firmly to the subjacent aspect of the sclerotic. The average thickness of the mass was ore inch and a-half. Beneath the sclerotic were the remains of the choroid, of a browner hue than natural; beneath this was a lenticular mass of melanosis. All that remained of the lens was a tough indurated mass of buff-coloured lymph (?). After prolonged search, no remains of the optic nerve could be detected. The sclerotic did not appear to hare giren way at any point.

Minute Anatomy of the Growth. The subconjunctiral (great) mass of the tumour required to be acted on by chlorine water before its elements could be well discriminated. It was then found to consist of cancer-cells, intervening granular matter, numbers of fine fat globules, and still unbleached pigmentary masses. The intraocular mass differed from the abore in containing no cancer-cells. Some of the muscular fibres of the external rcetus, which were examined, were seen to have lost all traces of strix, but had a uniform nebulous appearance.

Post Mortex Examivation. Ilead.-On opening the cranium, about two ounces of slightly bloody serum were found in the arachnoid cavity; the arachnoid was thickened here and thcre by old lymph. The pia mater was somewhat hypervascular. On the upper surface of the cerebrum was a small melanotic mass, which encroached slightly on the brain substance. No cvidence of disease was found in the brain. The optic nerve of the affected side differed from that of the sound side, in bcing smaller and more transparent. No melanotic cxtension had occurred from the orbit, nor was any secondary deposition found in this cavity itself. Lungs.-The right lung was consolidated and hepatised nearly throughout its substance, the character of the hepatisation being intermediate between that of the red and grey varicties, but approaching closer to the latter. Here and there a melanotic tumour was found in the interior of the lung, but a greater number were found at the surface, projecting from this in the form of disks. The arerage size of these growths was about that of a filbert. The lung-substance immediately around one of the deeper tumours was found not farther advanced in hepatisation than that at a considerable distance from it, and that around one of the superficial tumburs was found little more than highly congested. I was able to trace distinctly the pleural membrane over one of the projecting nodules of melanosis; it exhibited no extra vascularity. The left lung was at parts much congested, but not consolidated. Scattered through its substance were some melanotic tumours, but very few were apparent on the surface. Liver.-In this organ were several large masses of melanosis, their arerage size being that of a very large walnut. Some were of a deep Indian ink colour, and soft, others harder, lighter in tint, and showing a somewhat radiated structure. The former were so densely impregnated with pigment granules, that nothing else could be defined with the microscope ; in the latter, cancercells and nuclei were observed. 'The hepatic cells of the adjacent liver-substance were considerably filled with bright fat globules. Many of the mesenteric glands were much enlarged by melanotic degeneration. The kidneys and spleen appeared sound.

(4) NavoID CANCER (?). Auct. The claims of this species, although tacitly admitted by the nomenclature of eminent pathologists-" Carcinoma cirsoides", M/iiller: "carcinoma telangiectodes", Virchouc; " cavernous cancer", Esmarch - must still be regarded as doubtful.

Müller relates a case.

CA\&E. A woman of cachectic appearance had a deeply seated tumour in the arm; amputation was performed. This tumour consisted of " very considerable enlargements of softened blood-ressels and of blood extravasations." In the course of half a-year she died. In the abdomen were found great masses of grape-like (trüubigen) enlargements of ressels filled $w$ ith blood.

He further illustrates the subject by reference to a case of Walther's, which, not being very well known, I quote at some length.*

Case. A student had two congenital mother-marks on his right leg. One remained stationary; the other increased, and, "at his twentieth year, had a length of three inches, and a greaiest breadth of a little more than an inch and a half. It formed a flat tumour. The skin was here discoloured brown, playing into bluish; the surface of the tumour rough and uneven, permeated by many visible small vessels." Professor Walther extirpated it. The operation wound was a long while healing, and the smaller tumour threw out small fungous sprouts in the subcutaneous cellular tissue; the cicatrix of the operation never broke out again. About three years after the operation, he had considerable hæmoptysis, which occurred repeatedly, and in eleven days more he died.

At the autopsy, Professor Mayer found in the "panniculus adiposus a mass of oval, reddish, pretty consistent" bodies or fungi, mostly arrived at the size of a beanabout 20-25. Their simplest form was as follows : a process of the cellular tissue received a small vascular branch, which spread itself like a trce, and formed an oval vascular network. "Perfectly developed, they were consistent, externally and internally reddish, rich in blood, and showed, on section, some enlarged mouths of vessels." "On a section of the lungs, there were perceived sereral round defined bodies, which felt hard, and consisted principally of enlarged blood-vessels. This enlargement of the vessels was exhibited still more clearly when the lungs were placed in spirit. Then it was seen that these enlargements of the blood-vessels were not limited to those bodies, but pervaded in a less degrec the whole parenchyma of the lungs." "When mercury was injected into the arteries, reins, and air-tubes, it made its appearance at the greatly enlarged mouths of the blood-ressels and the bronchia." Professor Walther describes it as a case of fungus hæmatodes.

Cruveilhiert relates the following case:-

CAse. A lady had on her head a dozen or 60 soft navoid tumours, of about the size of a large nut, pulsating synchronously with the heart. At the inner side of her left thigh was a similar pulsating tumour, the size of a fist; one surrounded the upper part of the right humerus; one was situate on the left shoulder; whilst another was connected with the anterior extremity of the third rib. The patient ultimately dicd marasmatic. After death, the tumours of the head were found to be generated in the osseous tissue (which was gnawed through) of the vault and lateral regions of the cranium. The tumour of the humerus had destroyed nearly all the adjacent bone. The tumours of the thigh and shoulder were developed in the soft parts. "All the pulsatile tumours were constituted by a cavernous tissue, whose fibrous areolæ were filled with blood. All the other organs of the body were healthy.

Cruveilhier, in his most recent work, $\$$ denies the possibility of erectile tumours running a malignant course. He considers "that the pulsatile tumours of bone are constituted by a cancerous tissue, ordinarily encephaloid"; and, citing the above case, draws an "impassable line of demarcation between erectile tumours and pulsatile tumours."

I have no doubt myself that all the cases which have been regarded as vascular tumours running a malignant course were really cases of encephaloid cancer, in which the vessels were developed in extraordinary number and degree. I am able to adduce a very remarkable case strikingly corroborative of this opinion.

Cass. Edward W., aged 61 years, entered the Middlesex

Journal der Chirurgie und Augenheilkunde, ron C. F. Grüfe und $\mathbf{P h}$ v. Walther, bd. v, p. 261 . Berlin : 1828

+ Crureilhier's "Anatomio Pathologique du Corps Humain" (1829-35), liv: xxxiii, pl. $1 v$.

Traité d'Anatomie Pathologique Générale, par J. Crupeilhier, tom. iif. Paris : 1856. 
Hospital some jears ago, for violent hrmatemesis, and, some time subsequently, for equally severe hæmaturia. Ever since he could remember, he had had a number of vascular tumours in different parts of his body. Over the outer third of the right pectoral muscle was one of the size of a small walnut; above it were two smaller ones; over the right deltoid muscle, one of about the size of a filbert. Above the right clavicle was one larger than cither of these. He had a small one in the dorsum of the cleft of the right thumb, and one over the first phalanx of the left ring finger; several small ones about the neck, and one above the left clavicle. On the inside of the left angle of the lip were one or two, and on the mucous membrane of the inside of the cheeks, deep back in the mouth, were two or three of about the size of a pea on either side. The left half of the tonguc was irregularly swollen out by venous growths. On the glans penis were sereral such tumours, of about the size of those inside the mouth.

Curiously enough, although suffering from the effects of fistula in ano, when I last saw him in the hospital, under Mr. De Morgan's care, he had never had bleeding from the rectum, excepting twenty years ago, but appeared now to be subject to prolapsus of the anus. He was a good deal emaciated, and had a sallow flabby look about his face. Numerous minute varicose veins supplied the healthy blush on the checks; in these were several very minute vascular prominences.

These nævoid tumours varied considerably in appearance, and in their relation to the cutaneous structures. Some were entirely bencath the skin, under which they felt like rolling, round, encysted tumours, made but little prominence, and were rather appreciable to the sense of touch than to that of sight. Some, on the other hand, had that peculiar pale venous-blue hue of the subcutaneous nacvi of children; whilst a third set formed rounded, thin, walled, dark, purple tumours. They could all be partially emptied of their blood by pressure, filling again when this was removed. None pulsated in the slightest degree.

Here, then, we have a multiple dissemination of nonmalignant tumours, which, by their presence, in all probability, in the hollow viscera, had given rise to severe local effects, but yet, after existing for years, had caused none of that undermining of the general health so often observed in conjunction with a single cancerous tumour, to all appearances, comparatively to these venous growths, innocuous by its mere local effects.

[To be continued.]

\section{COXSIDERATIONS RESPECTING THE OPERATION OF MALARIA ON THE HUMAN BODY.}

By C. Haxdined Joxes, M.B., F.R.S., Assistant-Physician to St. Mary's IIospital.

[Continued froin page tiro.]

6. There are numerous forms of disease which are capable of being produced by malaria besides those alluded to. Omitting any further mention of fevers, graduating, according to the intensity of the cause and the degree of predisposition, from intermittents into continued, we may notice dysentery and neuralgia as being as much modes of manifestation of malarious action as fevers. The almost constant supervention of dysentery on remittent fever is so well known that to adduce evidence would be merely tedious. Dr. McCulloch alludes to the not uncommon occurrence of a fit of neuralgia and a paroxysm of intermittent happening on alternate days, remindiug us of the double tertian. The case has been mentioned to me by one of the members of this Society of an officer, aged 23, who, having returned from Africa in ill health, had an attack of ague on Friday and on the following Sunday. On the next Tuesday, the day for the paroxysm, he had instead severe neuralgia of both forearms, continuing from the evening to the next morning. After this, the ague paroxysms recurred again. Dr. Copiand, whose world-wide experience makes his testimony especially valuable, recognises malaria as one of the most efficient causes of neuralgia. The same authority sustains also the opinion that rheumatism may result from malarious influence. I believe I have witnessed the same occurrence myself. That pestilential cholera is a malarious disease, closely allied to the pernicious fevers, I am fully conviuced, following the opinions of Bell, Dixon, Billing, and others. While cholera was epidemic in London in 1854, I had a severe attack of an aguish character; and the peculiar depression I then experienced continued for some weeks, until the disease passed away. I could only shake it off by going to Hamp. stead, where I immediately regained a degree of vigour, but lost it again as soon as $I$ returned to Paddington. From that period to the present, I may say that aguish disorder and neuralgic affections have been prevalent to a degree that I never knew before. Apoplectic and paralytic affections are known to occur as the results of the poisonous in. fluence we are considcring; and I beliere these morbid phenomena are of much significance in attempting to form an opinion respecting the general action of malaria. While I do not doubt that local determination of blood may hare some effect in cuusing the impiarment of the function of the nerrous structure, yet I think there is much ground for believing that both nerves and nerrous centres suffer primarily by the operation of malaria, sometimes in a way of irritation, but chiefly by enfecbling and debility. Slighter cases show this even more certainly than severer ones. In the Lancet for October $20 \mathrm{th}$, I have recorded two cases which appeared to be ordinary neuralgic affections of the upper extremitics, peculiar only in this, that the motor nerres of the muscles were involved to a considerable extent, and not only the sensory. IIere there could be no question of any congestion of the encephalon. A naval surgcon, a robust strong man, engaged at the Crimea, and especially in the Kertch expedition, got diarrhoca, and, soon after, paralysis of one arm came on, which lasted about a day, and then disappeared. An assistant-surgeon, who had been at Balaklava since the commencement of the war, was seized there with fever, and remained there till convalescent. He was invalided to return home, and, on reaching Constantinople, went on shore to make a few purchases. II orer-fatigued himself, and, on his return on board, was seized with paralysis of all his extremities, the intellect remaining perfectly clear. He arrived in England in this perfectly helpless state, unable to feed himself, or do anything for himself. In about two or three months, he recovered perfectly. The cases of two members of our profession hare bcen mentioned to me, who, after suffering remittent fever in the Crimea, became to a great degree idiotic. One of them imagiried he had two bodies, and, if any one sat near him, was fidgeted lest his second body should not have room enough. The other thought he had two heads. Another gentleman, who suffered also from fever in the Crimea, and was very much prostrated both bodily and mentally when he returncd home invalided, regained his bodily health very well after some months, but was far from having the same mental energy that he used; he could not apply himself with attention to auything, and could not use the same muscular excrtion as before. In these cases, one cannot but recognise a special state of cerebral debility, or impairment of its functional power, quite apart from all suspicion of congestion. I must adduce the following instances from Dr. McCulloch, on account of the great importance of the point. In a situation exposed to malaria, and never free from its diseases, while the other members of a large family had the intermittent under different but ordinary forms, two were attacked with paralytic affections suddenly; the one in the leg and thigh; the other in the arm. I viewed these palsies as modes of the apoplexy of intermittent; and the judgment was confirmed by the almost spontancous disappearance of the disease in both, and the immediate establishment of the regular quo. tidian. (Vol. i, p. 292.) The apoplectic state is not limited either to the first attack or to the acuter forms of these fevers, although in Italy that appears to be the most 